\title{
Retinoid metabolism in human leucocytes
}

\author{
BY D. SKLAN ${ }^{1}$, S. TRIFON ${ }^{1}$, O. KEDAR ${ }^{1}$, N. VAISMAN $^{2}$ AND Y. BERNER ${ }^{3}$ \\ ${ }^{1}$ Faculty of Agriculture, Hebrew University, Rehovot 76100, Israel \\ ${ }^{2}$ Pediatric Division B, and ${ }^{3}$ Hartzfeld Geriatric Division, Kaplan Hospital, Rehovot 76100, Israel
}

(Received 13 January 1994 - Accepted 10 October 1994)

\begin{abstract}
Leucocytes from subjects from 0 to 80 years old were separated into mononuclear and granulocyte fractions and the retinoids and retinoid-binding fractions were examined. Both leucocyte fractions were found to contain retinol, retinoic acid and an additional retinoid; retinoic acid comprised $40 \%$ of retinoids in some samples. The protein fractions containing retinoids included a $200 \mathrm{kDa}$ protein and several 14-18 kDa proteins. Plasma concentrations of retinol changed little with increasing age. In contrast, leucocyte concentrations of retinoids and retinoid-binding proteins increased quadratically with age. However, in granulocytes from young children retinoids were almost undetectable.
\end{abstract}

Retinoid metabolism: Leucocytes: Human

The role of retinoids as possible regulators of the immune response was originally indicated by observations that vitamin A deficiency and malnutrition were accompanied by increased incidence and severity of neoplasia, and by increased susceptibility to infectious diseases, apparently due to impaired immune response (reviewed by Shapiro \& Edelson, 1985; Friedman \& Sklan, 1993). From these studies it appears that all immune responses studied have been shown to be affected by retinoid deficiencies. In addition, all physiologically occurring retinoids influence immune responses. The extent of these effects, however, differs between retinoids. The response of antibody production and T-lymphocyte proliferation to increasing levels of dietary vitamin $A$ is bell-shaped with decreased activity at low and high vitamin A intakes (Friedman \& Sklan, 1989). However, as most studies have been conducted to evaluate dietary effects of retinoids on the immune response, direct effects of retinoids on cells of the immune system are difficult to assess (Shapiro \& Edelson, 1985; West et al. 1991; Friedman \& Sklan, 1993).

Recent studies have focused on vitamin A effects on differentiation of myeloid leukaemic cells and malignant lymphoid cells (Lotan, 1980; Buck et al. 1990; Adelman et al. 1991). In normal lymphocytes it has been shown that retinoids are key cofactors in both B- and T-lymphocyte activation (Buck et al. 1990; Blomhoff et al. 1991; Garbe et al. 1992). However, the mechanisms of the effects of retinoids in leucocytes have not been clarified. The aims of the present study were to examine for the presence of retinoid-binding proteins in leucocytes and determine retinol and retinoic acid concentrations in different cellular fractions. As the study progressed, differences in concentrations of retinoids in leucocytes with age became apparent, and these were examined in more detail.

\section{METHODS}

\section{Subjects and treatments}

Subjects were included providing there was no apparent nutritional inadequacy or infectious disease, and that they were within $10 \%$ of ideal weight for height. Subjects ranged from 0 to 80 years old and were distributed as follows : (1) six children $0-5$ years old 
hospitalized for non-infectious reasons; (2) six youths aged 11-18 years, pre-operative blood; (3) nine adult subjects $25-45$ years old, health and laboratory personnel; (4) eleven elderly subjects $65-80$ years old, bedridden in a geriatric ward. No inflammatory processes were evident in any of the subjects.

Blood was obtained after an overnight fast by venipuncture and taken into tubes containing EDTA. For cell preparation the blood was layered over $5 \mathrm{ml}$ Polymorphoprep solution (density $1.068 \mathrm{~g} / \mathrm{ml}$; Nycomed, Oslo, Norway) and centrifuged at $500 \mathrm{~g}$ for $30 \mathrm{~min}$. The mononuclear-cell-rich band at the interface was removed, suspended in $\mathrm{NaCl}$ $(9 \mathrm{~g} / 1)$ in phosphate buffer $\mathrm{pH} 7 \cdot 4$ and resedimented. A granulocyte-rich fraction was prepared by reconstituting the bottom fraction from the centrifugation described above with $\mathrm{NaCl}$-phosphate buffer. Fractions were examined morphologically for purity.

\section{Chemical methods}

Cells were lysed by ultrasonication and in order to separate retinoid-binding proteins ionexchange chromatography was carried out on diethylaminoethyl (DEAE) cellulose (DE 52; Whatman, Maidstone, Kent) using a $\mathrm{NaCl}$ gradient from 0 to $250 \mathrm{~mm}$. Absorption was determined at $280 \mathrm{~nm}$ and fluorescence with excitation at $360 \mathrm{~nm}$, and emission at $470 \mathrm{~nm}$ was determined in the eluent.

Further separation of proteins was by gel filtration using a Sephadex G-150 (Pharmacia Ltd, Uppsala, Sweden) column or Fractogel-TSK column (Merck GmbH, Darmstadt, Germany) with absorption and fluorescence determined in the eluent as described above. Columns were calibrated for molecular weight with protein standards from 10 to $200 \mathrm{kDa}$ and retinoid-binding proteins were determined from the intensity of retinol fluorescence (Sklan \& Lotan, 1984).

Identity of some proteins was tested by radial immunodiffusion carried out as described by Mancini et al. (1965).

Retinoids and vitamin $\mathrm{E}$ were determined in plasma and cells, following extraction by reversed-phase HPLC using a $\mathrm{C}_{18}$ column with retinoids quantified by fluorescence spectroscopy with excitation at $330 \mathrm{~nm}$ and emission at $470 \mathrm{~nm}$. Retinyl acetate added before extraction served as an internal standard (Sklan \& Halevy, 1984).

This study was approved by the Human Subjects Committee of Kaplan Hospital.

Continuous variables were analysed by the method of least squares ANOVA. Significance was $P<0.05$ unless otherwise stated.

\section{RESULTS}

Leucocytes were separated into two fractions, mononuclear cells and granulocytes; these cells were lysed and the contents examined by gel filtration. This revealed the presence of proteins binding retinoids with apparent molecular masses of $2000,75-80$ and $14-18 \mathrm{kDa}$ (Fig. 1). The fraction with the molecular mass of $75-80 \mathrm{kDa}$ showed precipitation on immunodiffusion against antibodies to albumin. The other fractions showed no reaction with these antibodies. DEAE ion-exchange chromatography and determination of retinoids by relative fluorescence revealed three to four peaks in granulocytes and two peaks in mononuclear cells (results not shown). The fractions eluting at a conductivity of 7-9 mS were examined by gel filtration and had molecular masses of 14-18 kDa. Examination of the retinoids indicated that the high-kDa fraction contained both retinol and retinoic acid and these retinoids were also found in the $14-18 \mathrm{kDa}$ fraction together with an additional retinoid eluting before retinol on the $\mathrm{C}_{18}$ column.

Vitamin A concentrations in plasma and leucocytes from subjects of several different ages were examined; plasma concentrations of vitamin A changed little with age (mean plasma concentration $1.48(\mathrm{SD} 0.18) \mu \mathrm{mol} / \mathrm{l})$. Concentrations of two retinoid-binding- 


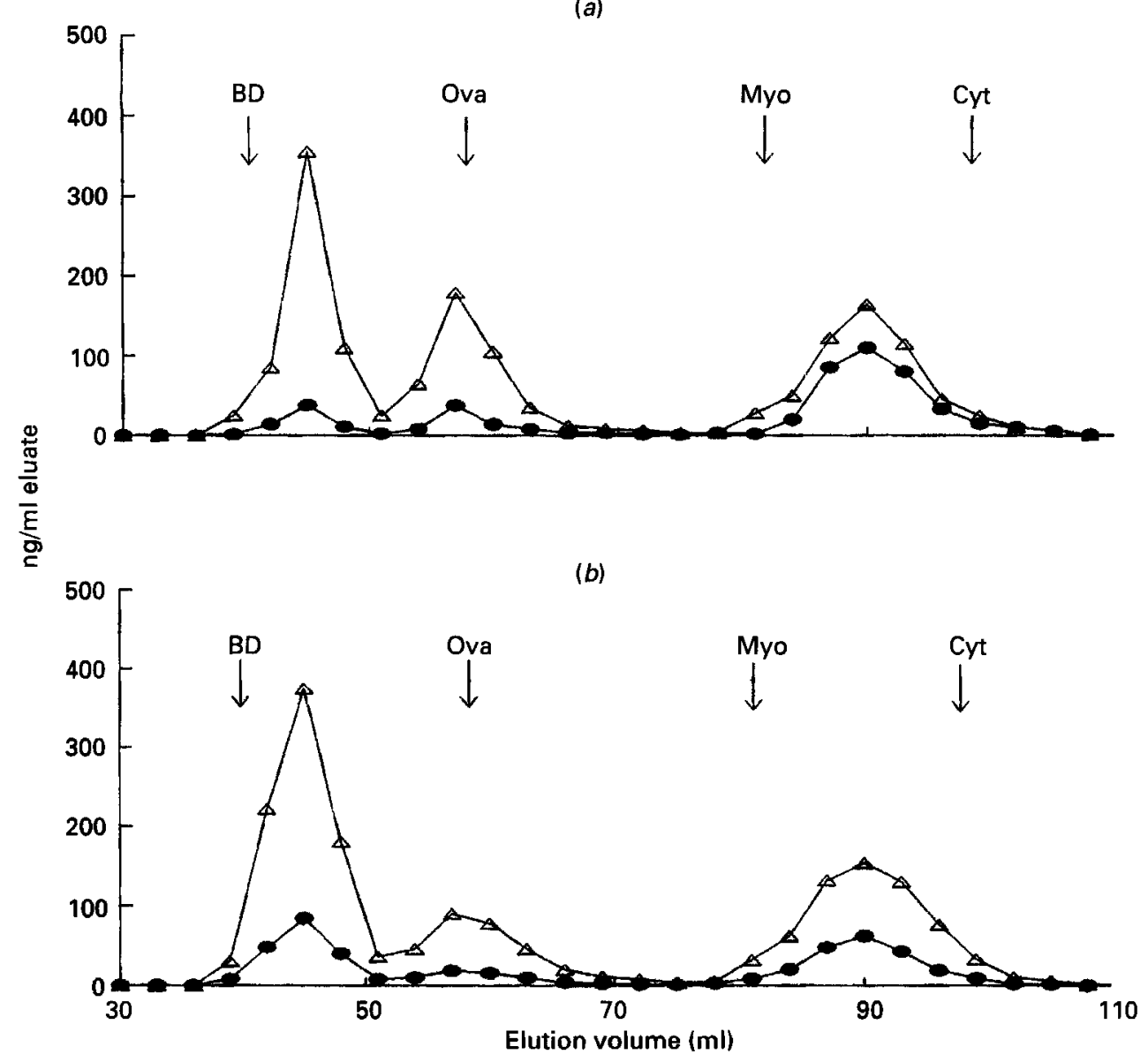

Fig. 1. Elution profiles of retinoid-binding proteins in lysates of (a) granulocytes and (b) mononuclear cells from adult subjects on a G-150 Sephadex column eluted with $0.1 \mathrm{M}-\mathrm{NaCl}$ containing $0.05 \mathrm{~mm}-\mathrm{Tris} \mathrm{HCl}$. $(\triangle)$, Retinol; (O), retinoic acid. For details of procedures, see p. 890 . BD, blue dextran; Ova, ovalbumin; Myo, myoglobin; Cyt, cytochrome C.

protein fractions, high molecular mass and the 15-18 $\mathrm{kDa}$ proteins in the two cell fractions are shown in Figs 2 and 3 together with retinol and retinoic acid concentrations in cells. Retinyl esters were not detected in leucocytes. The mononuclear cell fraction showed low concentrations of retinoids in young children, and retinoic acid was generally not detected. Concentrations of both retinoids increased with age, with the proportion of retinoic acid also increasing with age. Both retinoid protein fractions were found at high levels in elderly subjects and concentrations of retinoids were found to be related quadratically with age (Table 1).

Granulocytes from children had low to undetectable levels of retinoids, whereas in cells from older subjects retinoid concentrations increased, reaching up to $50 \%$ of concentrations found in mononuclear cells. Retinoic acid proportions increased in elderly subjects. In these cells retinoic acid comprised $30-50 \%$ of retinol levels and over $90 \%$ of the retinoids were found in the $14-18 \mathrm{kDa}$ fractions. Retinoid concentrations and the two retinoid-containing protein fractions were significantly quadratically, but not linearly, correlated with age (see Table 1). 


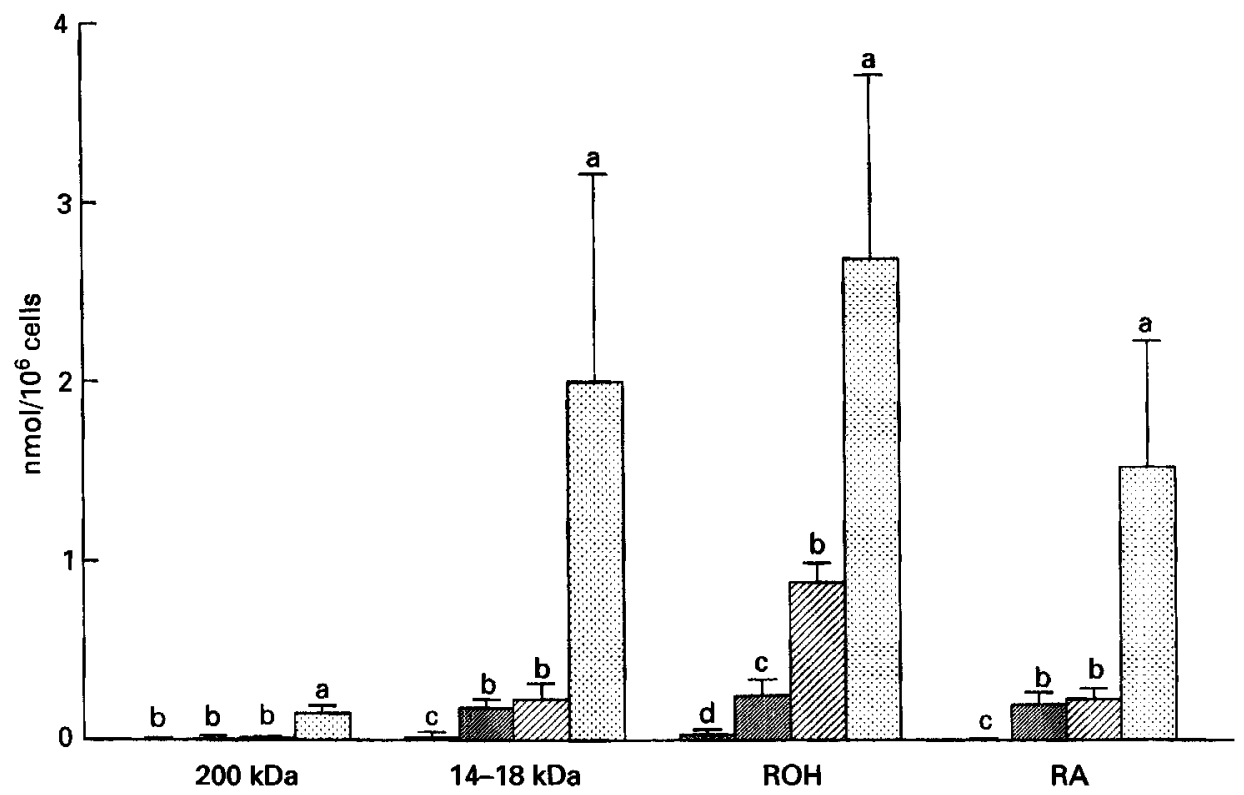

Fig. 2. Concentrations of retinoid-binding proteins (molecular weight $200 \mathrm{kDa}, 14-18 \mathrm{kDa}$ ), retinol (ROH) and retinoic acid (RA) in granulocytes from human subjects of different ages. Values are means with their standard

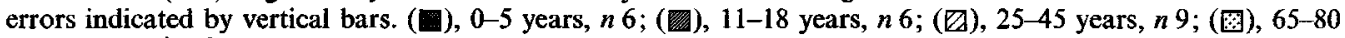
years, $n 11$. a, e, d Bars not sharing a common superscript letter were significantly different, $P<0-05$. For details of subjects and procedures, see pp. 889-890.

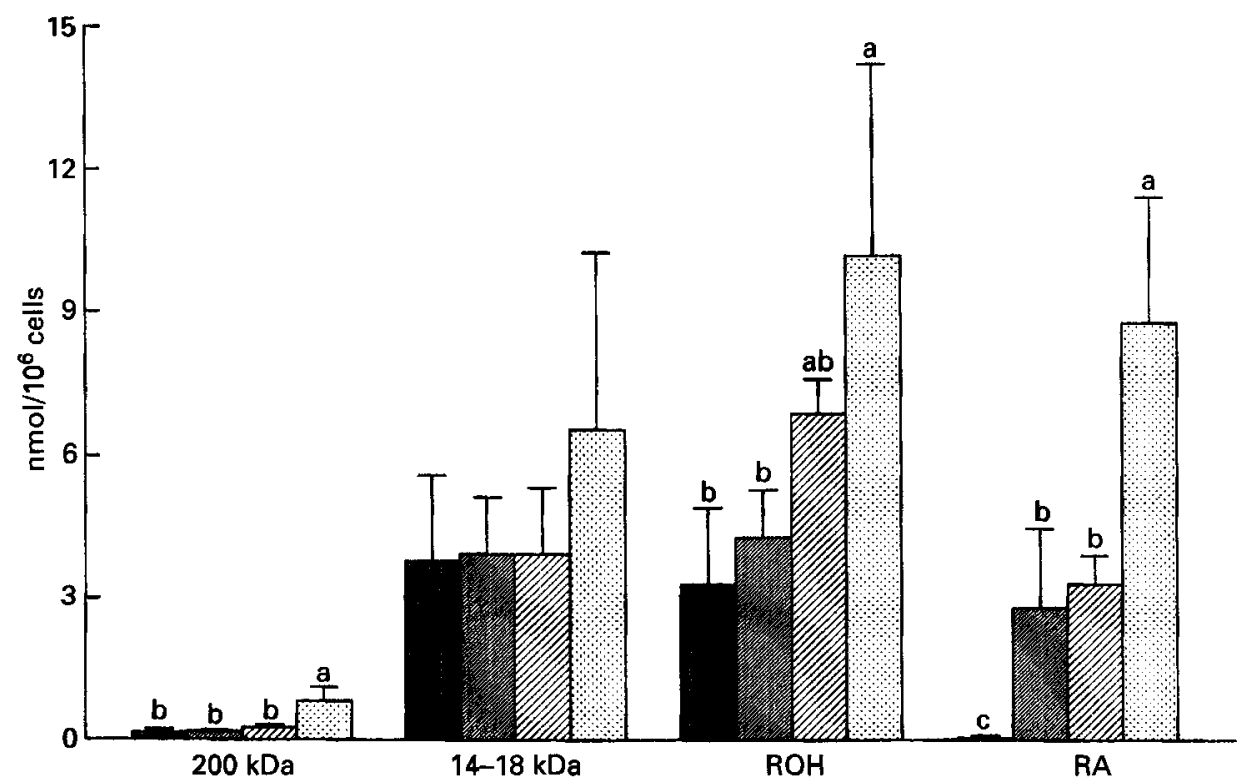

Fig. 3. Concentrations of retinoid-binding proteins (molecular weight $200 \mathrm{kDa}, 14-18 \mathrm{kDa}$ ), retinol (ROH) and retinoic aid (RA) in mononuclear cells from human subjects of different ages. Values are means with their standard errors indicated by vertical bars. ( $)$, 0-5 years, $n 6$; (圆), 11-18 years, $n 6$; (四), 25-45 years, $n 9$; (图), 65-80 years, $n 11{ }^{a, b, c}$ Bars not sharing a common superscript letter were significantly different, $P<0.05$. For details of subjects and procedures, see pp. 889-890. 
Table 1. Quadratic relationship between retinoids, retinoid-binding proteins and age in human subjects*

\begin{tabular}{|c|c|c|c|c|c|}
\hline Parameter... & $\mathbf{A}_{0}$ & $A_{1}$ & $\mathbf{A}_{2}$ & $\mathbf{R}_{\text {quad }}$ & $\mathbf{R}_{\text {lin }}$ \\
\hline Plasma retinol & $1 \cdot 387$ & 0.0081 & -0.001 & 0.83 & 0.56 \\
\hline $\begin{array}{l}\text { Granulocytes } \\
2000 \mathrm{kDa} \text { fraction } \\
14-18 \mathrm{kDa} \text { fraction } \\
\text { Retinol } \\
\text { Retinoic acid }\end{array}$ & $\begin{array}{l}0 \cdot 102 \\
1.085 \\
0 \cdot 76 \\
0.8375\end{array}$ & $\begin{array}{l}-0.1298 \\
-1.394 \\
-1 \cdot 126 \\
-1 \cdot 111\end{array}$ & $\begin{array}{l}0 \cdot 0351 \\
0 \cdot 4 \\
\mathbf{0} \cdot 4013 \\
0 \cdot 3175\end{array}$ & $\begin{array}{l}0.94 \\
0.94 \\
0.99 \\
0.96\end{array}$ & $\begin{array}{l}0.23 \\
0.27 \\
0.41 \\
0.20\end{array}$ \\
\hline $\begin{array}{l}\text { Monocytes } \\
2000 \mathrm{kDa} \text { fraction } \\
14-18 \mathrm{kDa} \text { fraction } \\
\text { Retinol } \\
\text { Retinoic acid }\end{array}$ & $\begin{array}{l}0.497 \\
6 \cdot 225 \\
1.963 \\
0.115\end{array}$ & $\begin{array}{l}-0.477 \\
-2 \cdot 365 \\
-1.455 \\
-0.296\end{array}$ & $\begin{array}{l}\mathbf{0} \cdot 138 \\
0 \cdot 575 \\
0 \cdot 138 \\
\mathbf{0} \cdot 591\end{array}$ & $\begin{array}{l}0.96 \\
0.91 \\
0.94 \\
0.91\end{array}$ & $\begin{array}{l}0 \cdot 18 \\
0 \cdot 28 \\
0 \cdot 31 \\
0 \cdot 44\end{array}$ \\
\hline
\end{tabular}

$\mathbf{R}_{\text {quad }}$, quadratic correlation coefficient; $\mathbf{R}_{\text {lin }}$, linear correlation coefficient.

* The parameters were fitted to an equation of the general type: $Y=A_{0}+A_{1} X+A_{2} X^{2}$.

Retinol and retinoic acid concentrations were correlated in both cell fractions $(r 0.65$ and 0.38). Furthermore, the retinol concentrations and retinoic acid concentrations in the mononuclear cell fraction were linearly correlated with the respective concentrations in granulocytes ( $r 0.36$ and 0.68 respectively).

\section{DISCUSSION}

The present study has demonstrated the presence of intracellular retinoids and retinoidbinding proteins in granulocytes and in mononuclear cells. The protein fractions binding retinoids were similar to those previously described in several cell types and consisted of a high-molecular-mass complex, a fraction containing albumin, which probably originated in the plasma, and several 14-18 kDa proteins which were not identified further (Sklan et al. 1982; Sklan \& Lotan, 1984). Proteins with 14-18 kDa protein-binding retinoids have been reported in many tissues and are probably cellular retinol-binding protein (cRBP) and cellular retinoic-acid-binding protein (cRABP) types I or II (Blomhoff et al. 1991; Wolf, 1991).

The retinoids in the $14-18 \mathrm{kDa}$ protein fraction were retinol, retinoic acid and an additional retinoid more polar than retinol, which was observed in some samples. Similar retinoids have been reported by Buck et al. (1991) in B-lymphocytes and T-lymphocytes and the additional retinoid may be 14-hydroxy-retro-retinol (Garbe et al. 1992). Both cell fractions separated here exhibited a higher proportion of retinoic acid than found in other tissues (Ito et al. 1974; Alam \& Alam, 1983). Buck et al. (1991) have shown that the halflife of retinoic acid is threefold longer in B-lymphocytes than that of retinol and this would influence the relative concentrations. The relatively high concentration of retinoic acid in both cell fractions suggests metabolism in these cells of retinol to retinoic acid which may well be the active form of retinol.

Retinoids and retinoid-binding proteins were not found in granulocytes from young children, although both proteins and retinoids were present in mononuclear cells. This raises the question as to whether the retinoids are essential for these leucocytes despite the demonstrations of cofactor properties in T- and B-cell activation (Blomhoff et al. 1992; 
Garbe et al. 1992). The presence of retinoic acid receptors in human leukaemia cells (Largman et al. 1989) and murine T-lymphocytes (Friedman et al. 1994) has been reported which suggests a role for retinoids in gene activation in these cells (Evans, 1988). However, it is unlikely that synthesis of retinoid-binding proteins is activated only in older persons. It is also possible that the genes for retinol-binding protein synthesis are present at birth but are expressed at levels that we were not able to detect in young children. This question could be resolved by studying the DNA. However, in contrast to the binding proteins which are synthesized in situ, retinoids would need to be transported to the cells and such transport was not apparent; these two processes could, however, be connected.

Concentrations of the retinoids and binding proteins in both cell types increased quadratically with age and were not parallel to plasma concentrations. This may have been influenced by vitamin supplementation in the elderly patients examined here and indicates both selective uptake and some storage capacity for retinoids and some control of binding protein synthesis. Increases in serum vitamin A in elderly populations have been previously reported (Garry et al. 1987; Comstock et al. 1988) and it has been suggested that vitamin A absorption is increased in elderly humans and animals (Hollander \& Dadufalza, 1990; Krasinski et al. 1990).

Higher concentrations of retinoids were found in mononuclear cells than in granulocytes which is compatible with the described larger retinoid effects on granulocytes than mononuclear cells (West et al. 1991; Friedman \& Sklan, 1993).

It thus appears that metabolism of retinoids in leucocytes is similar to other cells although specific roles for retinoids are not demonstrated.

\section{REFERENCES}

Adelman, D. C., Yen, T. Y, Cumberland, W. G., Sidell, N. \& Saxon, A. (1991). 13-cis retinoic acid enhances Blymphocyte differentiation in patients with common variable immunodeficiency. Journal of Allergy and Clinical Immunology 88, 705-712.

Alam, S. Q. \& Alam, B. S. (1983). Lipid peroxide, $\alpha$-tocopherol and retinoid levels in plasma and liver of rats fed diets containing $\beta$-carotene and 13-cis-retinoic acid. Journal of Nutrition 113, 2608-2614.

Blomhoff, H. K., Smeland, E. B., Erikstein, B., Rasmussen, A. M., Skrede, B., Skjonsberg, C. \& Blomhoff, R. (1992). Vitamin A is a key reguator for cell growth, cytokine production and differentiation in normal B cells. Journal of Biological Chemistry 267, 23988-23992.

Blomhoff, R., Green, M. H., Green, J. B., Berg, T. \& Norum, K. (1991). Vitamin A: new perspectives on absorption transport and storage. Physiological Reviews 71, 951-990.

Buck, J., Myc, A., Garbe, A. \& Cathomas, G. (1991). Differences in the action and metabolism between retinol and retinoic acid in B lymphocytes. Journal of Cell Biology 115, 851-859.

Buck, J., Ritter, G., Dannecker, L., Katta, V., Cohen, L., Chait, B. T. \& Hammerling, U. (1990). Retinol is essential for growth of activated human B cells. Journal of Experimental Medicine 171, 1613-1624.

Comstock, G. W., Menkes, M. S., Schober, S. E., Vuilleumier, J. P. \& Helsing, K. J. (1988). Serum levels of retinol $\beta$-carotene and $\alpha$-tocopherol in older adults. American Journal of Epidemiology 127, 114-123.

Evans, R. M. (1988). Steroid and thyroid hormone receptors as transcriptional regulators of development and physiology. Science 240, 889-895.

Friedman, A., Halevy, O., Schrift, M., Arazi, Y. \& Sklan, D. (1994). Retinoic acid promotes proliferation and induces expression of retinoic acid receptor- $\alpha$ gene in murine T-lymphocytes. Cellular Immunology 152 , $240-248$.

Friedman, A. \& Sklan, D. (1989). Antigen specific immune response impairment in the chick as influenced by vitamin A nutrition. Journal of Nutrition 119, 790-795.

Friedman, A. \& Sklan, D. (1993). Vitamin A and immunity. In Human Nutrition-A Comprehensive Treatise, vol. 8; Nutrition and Immunology, pp. 197-216 [D. M. Klurfeld, editor]. New York: Plenum Press.

Garbe, A., Buck, J. \& Hammerling, U. (1992). Retinoids are important cofactors in T cell activation. Journal of Experimental Medicine 176, 109-117.

Garry, P. J., Hunt, W. C., Brandrofchak, J. L., Vander Jagt, D. \& Goodwin, J. S. (1987). Vitamin A intake and plasma retinol in healthy men and women. American Journal of Clinical Nutrition 46, 989-994.

Hollander, D. \& Dadufalza, V. (1990). Influence of ageing on vitamin A transport into the lymphatic circulation. Experimental Gerontology 25, 61-65.

Ito, Y. L., Zile, M., Ahrens, H. \& DeLuca, H. F. (1974). Liquid-gel partition chromatography of vitamin A compounds; formation of retinoic acid from retinyl acetate in vivo. Journal of Lipid Research 15, 517-524. 
Krasinski, S. D., Kohn, J. S., Schaefer, E. J. \& Russell, R. M. (1990). Post prandial plasma retinyl ester response is greater in older subjects compared with younger subjects. Journal of Clinical Investigation 85, 883-892.

Largman, C., Detmer, K., Corral, J. C., Hack, F. M. \& Lawrence, H. J. (1989). Expression of retinoic acid receptor alpha mRNA in human leukemia cells. Blood 74, 99-102.

Lotan, R. (1980). Effects of vitamin A and its analogs (retinoids) on normal and neoplastic cells. Biochimica et Biophysica Acta 605, 3391.

Mancini, G., Carbonara, A. O. \& Heremans, J. F. (1965). Immunological quantitations of antigens by radial immunodiffusion. Immunochemistry 2, 235-254.

Shapiro, P. E. \& Edelson, R. L. (1985). Effects of retinoids on the immune system. In Retinoids: New Trends in Research and Therapy, pp. 225-235 [J. Saurat, editor]. Basel: Karger.

Sklan, D., Blaner, W. S., Adachi, N., Smith, J. E. \& Goodman, D. S. (1982). Association of cellular retinol binding protein and several lipid hydrolase activities with a vitamin A containing high molecular weight lipid-protein aggregate. Archives of Biochemistry and Biophysics 214, 35-44.

Sklan, D. \& Halevy, O. (1984). Vitamin A metabolism in chick liver: some properties of the cytosolic lipid-protein aggregate. British Journal of Nutrition 52, $107-114$.

Sklan, D. \& Lotan, R. (1984). Retinoid binding lipoprotein in neoplastic cells. Cancer Letters 22, 41-47.

West, C. E., Rombout, J. H. W. M., van der Zijpp, A. J. \& Sijtsma, S. R. (1991). Vitamin A and immune function. Proceedings of the Nutrition Society 50, 251-262.

Wolf, G. (1991). The intracellular retinol binding proteins: an overview of their functions. Nutrition Reviews 49 , $1-12$. 